\title{
COMPRESSIVE DEFORMATION BEHAVIOR OF AN ULTRAFINE/NANO GRAINED AZ31 MAGNESIUM PROCESSED BY ACCUMULATIVE BACK EXTRUSION
}

\begin{abstract}
An AZ31magneium alloy was processed through accumulative back extrusion (ABE) process at $280{ }^{\circ} \mathrm{C}$ up to six passes. Compressive deformation behavior of the processed materials was studied by employing uniaxial compression tests at room temperature. The results indicated that grains of $80 \mathrm{~nm}$ to $1 \mu \mathrm{m}$ size were formed during accumulative back extrusion, where the mean grain size of the experimental material was reduced by applying successive ABE passes. A deformation texture characterizing with the basal plane mainly lie inclined to the deformation axis was developed. Compressive yield and maximum compressive strengths were measured to increase by applying successive extrusion passes, while the strainto-fracture dropped. The evolution of mechanical properties was explained relying on the grain refinement effect as well as texture change. It was described that the share of different deformation mechanisms and developing of shearing regions near the grain boundaries may influence the deformation behavior of the ultrafine/nano grained AZ31 alloy.
\end{abstract}

\section{Introduction}

Due to their energy-efficient properties, the use of magnesium alloys in industrial fields, such as the automotive and aerospace industries, has gained much attention. However, the application of magnesium alloys is greatly limited because of their relatively low strength and ductility. An effective way to improve the mechanical properties of magnesium alloy is to refine the grains. It was shown for pure magnesium that the Hall-Petch slope, ( $\mathrm{k}$ from the relationship: $\sigma=\sigma_{0}+\mathrm{kd}^{0.5}$ ), is quite higher than that of pure aluminum, so it is much more effective to enhance the strength of $\mathrm{Mg}$ alloys by simply refining the grain size [1].

Modification on thermo mechanical treatment enables obtaining fine grained microstructures [2, 3]. As the race for better materials performance is never ending, attempts to develop viable techniques for microstructure refinement continue. Further refining of grain size requires, however, application of extreme value of plastic deformation on material. Accordingly, a possible avenue for microstructure refinement of metals is severe plastic deformation (SPD), which has been widely used to fabricate ultrafine/nano grained metals and alloys through introducing a large plastic strain into a bulk metal. Previous researches have shown that the processing of magnesium alloys by SPD techniques is challenging [46] and the related property enhancement is limited by three main factors: First, the processing of many magnesium alloys are relatively difficult at low temperatures because of their low symmetry hexagonal crystal structure, stimulating the development of substantial cracking or segmentation. Second, SPD processing should be carried out at high temperatures to prevent cracking. As a result, the occurrence of dynamic recrystallization and growth occur inevitably and thereby may diminish the grain refinement effect. Third, as grain refinement may also cause variations in crystallographic texture, the postSPD mechanical properties result from combined effects of grain refinement and texture changes. Furthermore, it has been demonstrated that the degree of grain refinement by SPD, itself, is strongly coupled to the development of texture and substructural evolutions $[7,8]$. It has been proposed that grain refinement is primarily the result of the interaction of shear plane with texture and the crystal structure, with a secondary role coming from the accumulation of redundant shear strain during severe deformation [8].

Reported results on the mechanical properties of SPDed magnesium alloys illustrated that a miscellaneous combination of strength and ductility alterations may be obtained, depending on synergistic or antagonistic effects of grain refining and texture change [9-13]. Furthermore it was recognized that the Hall-Petch parameters are texture dependent so that easy activation of basal slip introduces lower values, while inhibition of basal slip leads to higher values [11]. Kim et al. [9] reported that the yield stress of an wrought AZ61 alloy processed by eight equal channel angular pressing (ECAP) passes dropped appreciably as compared to the initial material, while the tensile ductility was significantly increased. The latter observation describes a case where the texture softening is dominant over the strengthening due to grain refinement. However, results of opposite trend were obtained by Xing et. al. [10] and Zuberova et. al. [12], where severe plastic deformation of AZ31 alloy gave rise to an increased strength accompanied by minor ductility. Dissimilarly, the results

* FACULTY OF MECHANICAL ENGINEERING, SHAHID RAJAEE TEACHER TRAINING UNIVERSITY, TEHRAN, IRAN

** SCHOOL OF MATERIALS \& METALLURGICAL ENGINEERING, UNIVERSITY OF TEHRAN, TEHRAN, IRAN

*** INSTITUTE OF METALLURGY AND MATERIALS SCIENCE, POLISH ACADEMY OF SCIENCES (PAS), 25 REYMONTA STREET, 30-059 KRAKÓW, POLAND

\# Corresponding author: mfatemi@ut.ac.ir 
reported by Miura et. al. [13] on multi-axial forging of AZ61 alloy implied that although the tensile strength increased with a decrease in grain size, the ductility was not spoiled.

Summarizing related literature showed a complex picture of microstrctural characteristics that dictate the mechanical behavior of SPDed material [13-17]. Rare researches could be found in the literature discussing the mechanisms prominent during mechanical testing of ultrafined/nano $\mathrm{Mg}$ based alloys. It is generally accepted that grain refinement leads to a decrease in strain hardening as yield strength is increased [18], however, Ghosh and Yang [19] believe that the combined effect of increased strain rate sensitivity and strain hardening may offset the loss in ductility in AZ31 magnesium alloy. In addition, features of the microstructure, such as grain boundary and dislocation structures, could have important effects on mechanical properties. Wang and Ma [18] suggested that the design and processing of a bimodal or even multi-modal grain structure is a profitable approach for developing new materials. They made the point that a uniform and extremely fine nanocrystalline structure is neither necessary nor beneficial for properties and applications, if a high ductility, in addition to the high yield strength is desired.

The literature is clear, on the fact that the flow stress behavior of magnesium in compression usually differs markedly from that seen in tension. For example, the contribution of twinning, strain rate sensitivity and plastic instability of $\mathrm{Mg}$ alloys in compression is different from that in tension $[19,20]$. Very few systematic researches could be found in the literature focusing on the compressive deformation behavior of ultrafine/ nano grained magnesium alloys. The results reported by Zúberová et. al. [20] indicated that compressive yield strength of an AZ31 alloy was increased after applying four ECAP passes. On the other hand, strain-to-failure was found to drop with decreasing grain size. However, no explanation was given for the latter observation.

A new continuous SPD process, so-called accumulative back extrusion process (ABE), which is appropriate for production of ultrafine/nano grained bulk material has been introduced by two of the present authors [21]. Previous works mainly dealt with the developed strain patterns [22], microstructure [23, 24] and texture evolutions [25] during $\mathrm{ABE}$ processing. The present research was initiated to examine the compressive deformation behavior of a wrought AZ31 magnesium alloy subjected to various ABE processing. Moreover, the effect of number of passes has been evaluated through discussing combined influence of grain refinement and texture evolution.

\section{Experimental procedure}

A commercial AZ31 alloy (Mg-2.9Al-0.9Zn-0.7Mn, $\% \mathrm{wt}$ ), received in the form of rolled plate, was used as experimental alloy. Cylindrical samples for $\mathrm{ABE}$ processing were machined with the dimensions of $\mathrm{H} 8 \times \Phi 18 \mathrm{~mm} 2$. Briefly, the first step of ABE consists of the back extrusion of the workpiece into the gap between the inner punch and the die. In the second step the back extruded material is forged back to the initial cross section by the outer punch completing one $\mathrm{ABE}$ cycle. The previous work showed that an average equivalent strain of 2 is induced during each step [22]. ABE process was conducted at a ram speed of $5 \mathrm{~mm} / \mathrm{min}$ and temperature of $280^{\circ} \mathrm{C}$. According to the relatively low stroke speed the temperature increasing during extrusion was ignored. The $\mathrm{MoS}_{2}$ spray was used to reduce the friction between the work piece and the tool surfaces. The initial material showed a mean grain size of $25 \mu \mathrm{m}$ (Fig. 1a). The texture of initial material was illustrated in Fig. 1b, where a strong fiber texture with most of the basal planes aligned parallel to the RD-TD plane. For all the samples, the center of the rectangular cross section was considered for representative metallographic observations (as displayed in Fig. 2a). The microstructures of the deformed material were examined through optical microscopy, transmission electron microscopy (TEM) and field emission scanning electron microscopy (FESEM). The SESEM study was carried out using a Zeiss Ultra Plus microscope operated at $10 \mathrm{kV}$. The TEM investigation was performed using a Philips CM 20 microscope worked at $200 \mathrm{kV}$. A slice of the ABEed work-pieces was first cut parallel to the extrusion direction. The slice was then thinned by grinding to a sheet with $100 \mu \mathrm{m}$ thickness. The TEM samples were then mechanically polished using a twin-jet polishing unit. The perforation was done by a solution of $1 \%$ perchloric acid, $99 \%$ ethanol at a polishing temperature of $275 \mathrm{~K}$.

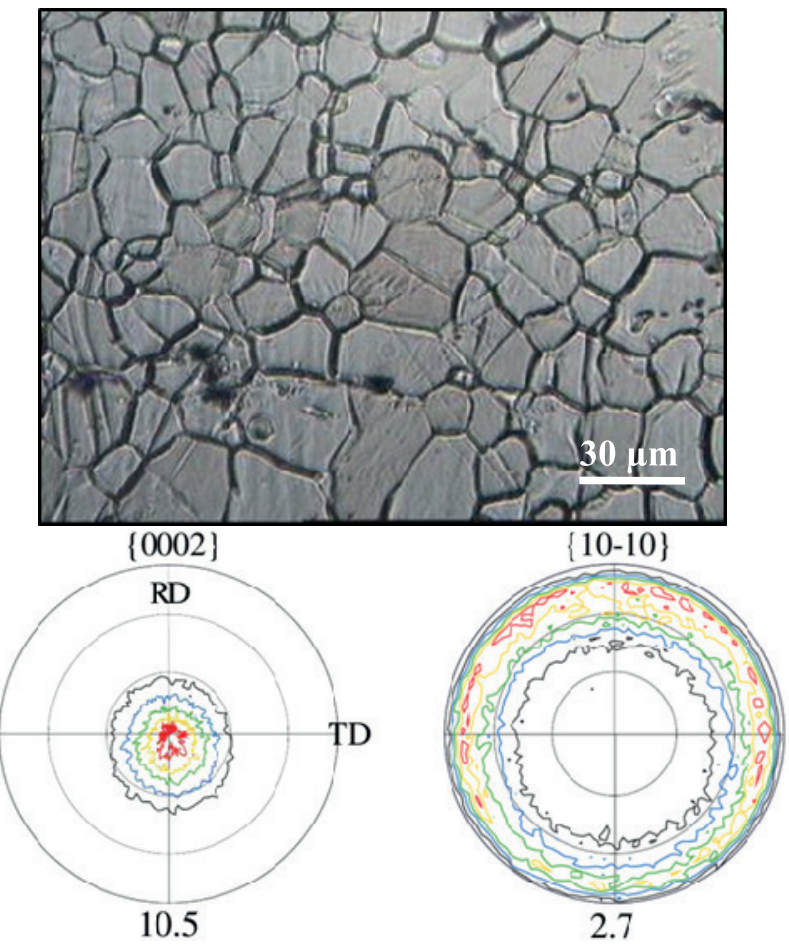

Fig. 1. a) Initial microstructure, b) measured pole figures of the experimental as-rolled AZ31 alloy

Cylindrical samples having a diameter of $5 \mathrm{~mm}$ and a height of $7.5 \mathrm{~mm}$ were used for compression tests. Samples prepared from as-received rolled material were taken parallel to the rolling axis. Samples from the ABE processed material was machined parallel to the ABE direction (as shown in Fig. 2b). Compression tests were performed using a universal testing machine at room temperature with an initial strain rate of $10^{-4} \mathrm{~s}^{-1}$. After the test, the samples were sectioned parallel to deformation direction, grinded, 
polished, and etched by Acetic Picral solution for further microstructural studies.
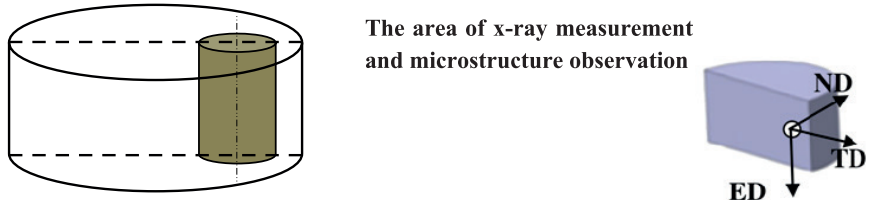

Fig. 2. Schematic illustration of the orientations of compression specimens used in deformation tests. (left) and locus of characterization (right

\section{Results and discussion}

The microstructural observations demonstrated that an outstanding grain refinement took place through ABE processing, where a relatively homogeneous grain refinement was achieved after sixth pass. TEM observation showed that recrystallized areas include grains of $80 \mathrm{~nm}$ to $1 \mu \mathrm{m}$ with mean size of $150 \mathrm{~nm}$. Figs. $3 \mathrm{a}$ and $3 \mathrm{~b}$ typically shows the microstructure of the ABE processed AZ31 alloy up to two and four passes, respectively. The ultrafine/nano grains developed during deformation were depicted in Fig. $3 c$. As the experimental alloy was processed by successive passes the coarse grain was substituted by fine recrystallized grains and more homogenous microstructure was obtained. The average grain sizes were measured as about 5, 2 and $0.5 \mu \mathrm{m}$ after processing of one, two and six ABE passes, respectively.
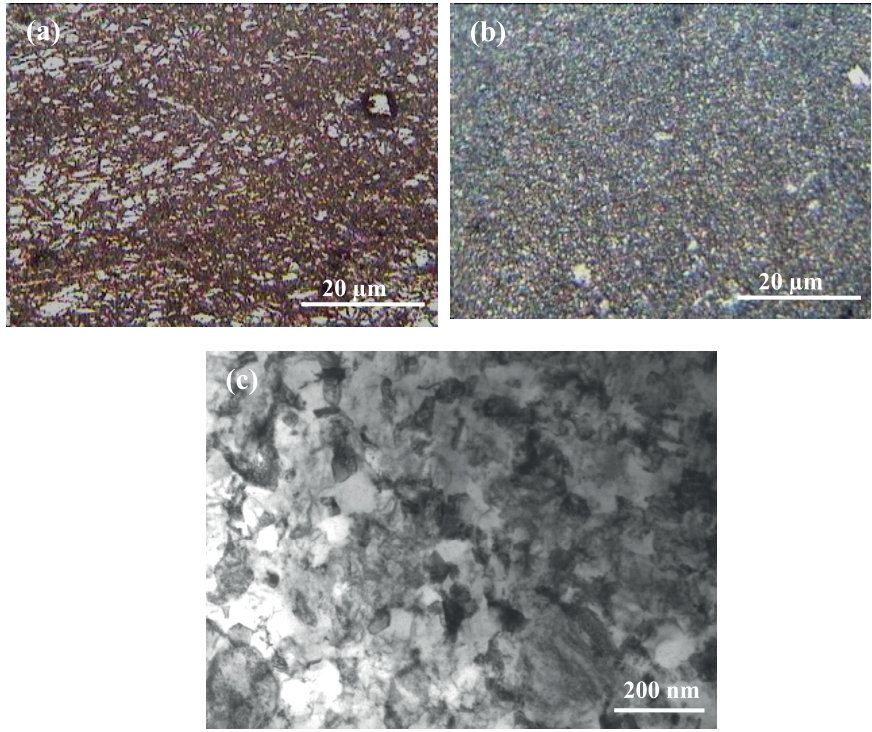

Fig. 3. Microstructure of the experimental alloy deformed up to a) two, b) four passes at $280^{\circ} \mathrm{C}, \mathrm{c}$ ) ultrafine/nano grains formed during $\mathrm{ABE}$ processing

The basal, prismatic and pyramidal pole figures of the sample deformed by different $\mathrm{ABE}$ passes were measured. The results were presented elsewhere [25], however, for the sake of convenience, the pole figures from the materials after the first and fourth passes are including in Fig. 4. As realized the original texture (Fig. 2b) was completely replaced and a new texture developed during the first pass. This is connected to the high shear strain magnitude imposed during $\mathrm{ABE}$ deformation [12]. The obtained ABE texture corresponds to the basal poles lying $\sim 40^{\circ}$ away from the transverse direction (TD) in the ED-TD plane and $66^{\circ}$ from the normal direction (ND) in the TD-ND plane, while the maximum of prismatic planes were revealed at $40-50^{\circ}$ in the TD-ED plane. These texture components mostly place the magnesium crystal inclined to the ABE axis. The post-ABE texture may be discussed relying on the presence of favorable initial basal texture, where the c-axis is mostly oriented by $40-50^{\circ}$ from the shear direction during $\mathrm{ABE}$ [22]. With the application of subsequent passes, there is a tendency of the basal plane lying parallel to TD, while the orientation of prismatic planes shows a random distribution around ND. Accordingly, after four passes it is evident that the most noticeable texture includes fiber basal texture oriented almost parallel to the transverse direction, and $<10-10>$ perpendicular to the ED. (a)

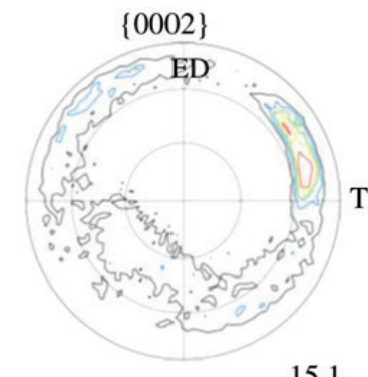

15.1

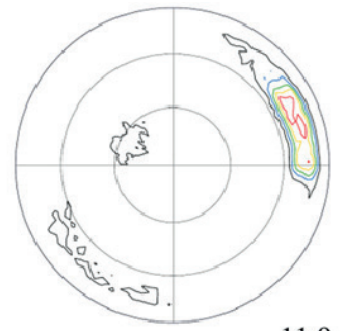

11.9
$\{10-10\}$

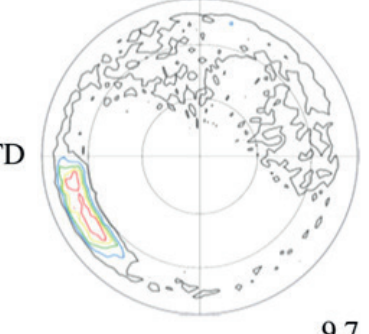

9.7

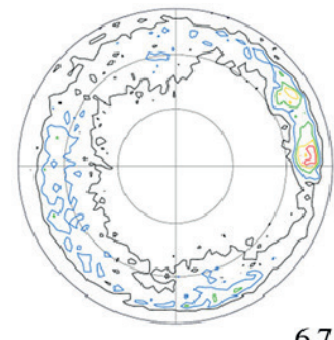

6.7
Fig. 4. (0002) and (10-10) pole figures of the texture of the experimental alloy ABEed up to a) one, b) four passes [25]

Fig. 5 depicted the compressive true stress-strain curves obtained from the as-received as well as ABEed samples. As can be seen the mechanical properties was significantly altered after deformation. The data of yield stress (YS), maximum compressive strength (MCS) and fracture strain are summarized in Fig. 5a. As simply seen, the yield stress increases almost two times after the first pass. After that it continues to be increased as subsequent passes were applied. The MCS slightly increased after the first pass, while it dropped by applying the second pass and continue to ascend again by subsequent passes. The fracture strain was decreased from 0.17 for as-received material to below 0.05 after six ABE passes. In case of pure magnesium it was reported that ECAP processing resulted in a ultrafined microstructure $\left(\mathrm{d}_{\mathrm{ave}}=0.8 \mu \mathrm{m}\right)$ accompanied with a enhanced both MCSand fracture strain [26]. Similar results were obtained by Ghosh and Yong [27] for an AZ31 alloy deformed by Alternate biaxial reverse corrugation. It is worth noting that the ABEed alloy exhibits serrated flow during compression which resembles that observed by Trojanova and Caceres in aged 

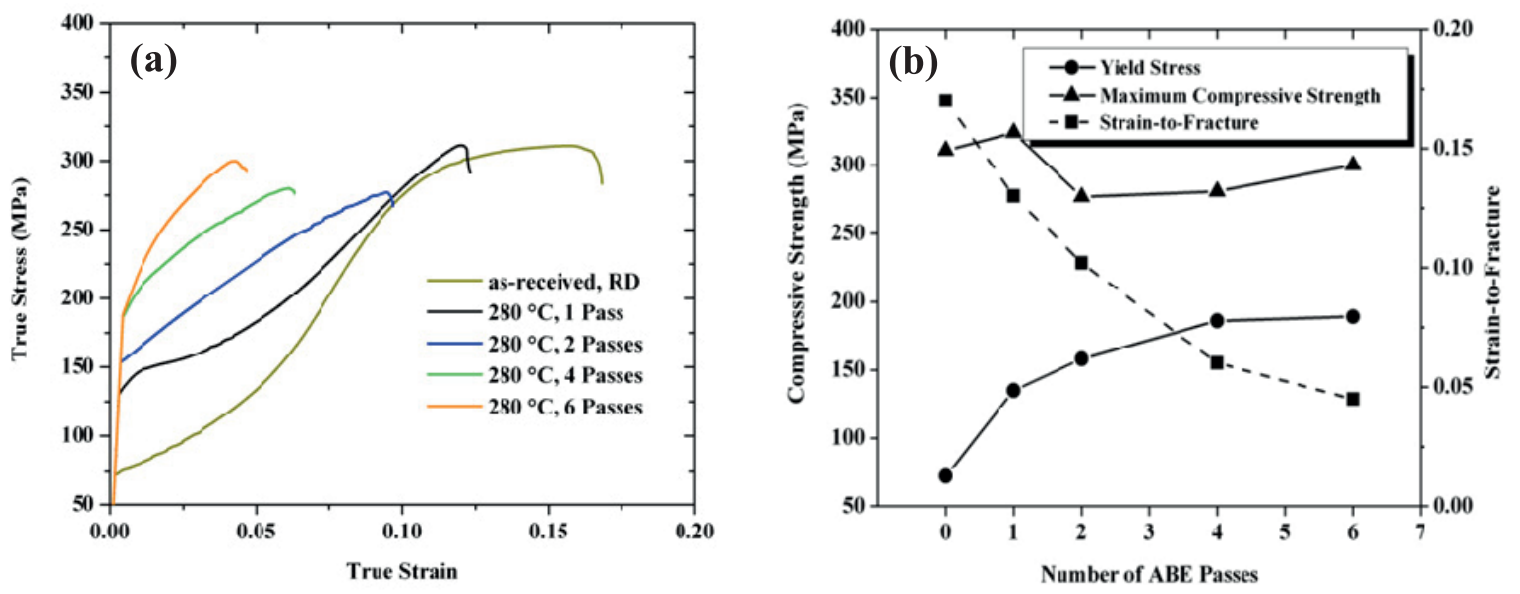

Fig. 5 a) True stress versus true strain at room temperature for as-received and processed experimental alloy, b) Variation of the yield stress, MCS and fracture strain with the number of ABE passes
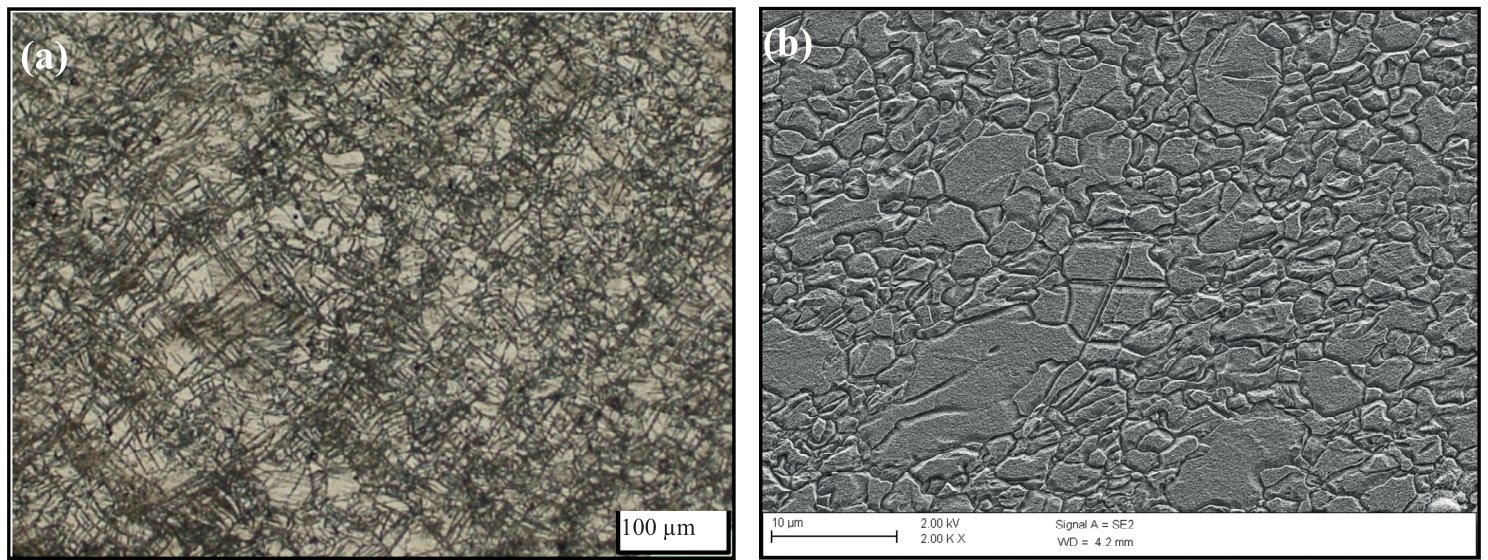

Fig. 6. The microstructure of a) as-received, b) four-pass ABEed experimental alloy deformed to 0.05 compressive strain

AZ91 magnesium alloy [28, 29]. They related the latter phenomenon to the strain aging of $\mathrm{Al}$ atoms and development of small bands to the point of suppressing the attendant homogeneous deformation.

One way to quantify the texture data is to use the crystallite orientation distribution function, which essentially describes the frequency of occurrence of particular orientations in a three-dimensional (Euler) orientation space. To identify the degree to which twinning and/or slip systems contribute during compressive deformation of ABEed material, the ODFs were obtained from $x$-ray diffraction texture data on the basis of spherical harmonics with positivity correction according to Dahms and Bunge [30]. Accordingly, the crystallographic plane and direction which lie, in most of grains, parallel to the extrusion direction of ABEed samples could be defined. The defined directions correspond to the deformation axis of the compression samples. The results were given in Table 1.

In the as-received material most grains have basal poles aligned with almost perpendicular to the RD, which favors the tensile twinning during compressive loading [31]. Therefore, the deformation during compression along the RD will be accommodated mostly by tensile twining. The strain hardening behavior observed along the RD is consistent with the activation of twins, i.e. a plateau region with relatively steady stress followed by an upward curvature with a high hardening rate. According to the
TABLE 1, the orientation factor calculated for the activation of twinning is still high enough in single-pass processed material. However, it should be noted that due to the grain refinement introduced during $\mathrm{ABE}$, the critical stress required for twinning was significantly increases. This may lead to a marked increase in yield strength. Microstructure investigation (Fig. 6) showed the prevalence of twinning in the as-received alloy, whereas the twinning was suppressed in the processed material. This caused the shape of the flow curve to change from "concave" for the as-received to "convex" for the processed samples.

As subsequent passes were applied, the fraction of DRX increased and the mean grain size of the ABEed alloy markedly lowered. This may help to explain the higher yield stress govern the occurrence of twinning during compressive loading. Moreover, the latter was accompanied by a change in flow curve shape. Meyer et. al. [32] pointed out that grain size dependence of twinning stress is significantly larger as compared to slip stress. Also, with increasing defamation passes, the intensity of basal texture is weakened (see Fig. 4), thus the share of easy glide on basal plane during deformation is limited. Previous works has denoted that the occurrence of twinning is stopped in AZ31 alloy at a grain size of $3 \mu \mathrm{m}[19,33]$ and $3.4 \mu \mathrm{m}[34]$. However, present results shows evidence of twins at grains as fine as 1-2 $\mu \mathrm{m}$ (Fig. 6). 
Orientation factors calculated for multi-pass ABEed AZ31 alloy considering the related deformation axis

\begin{tabular}{|c|c|c|c|c|c|c|c|c|c|c|c|c|c|c|}
\hline & $\mathbf{g}\left\{\varphi_{1}, \varphi, \varphi_{2}\right\}$ & def. axis & \multicolumn{3}{|c|}{ twinning } & \multicolumn{3}{|c|}{ basal slip } & \multicolumn{3}{|c|}{ prismatic slip } & \multicolumn{3}{|c|}{ pyramidal slip } \\
\hline 0 & $\begin{array}{l}\{81,0,12\} \\
\{81,0,57\}\end{array}$ & $\begin{array}{l}\simeq(\mathbf{0 0 0 1}) \\
\langle 1 \overline{2} 10\rangle\end{array}$ & \multicolumn{2}{|c|}{$\begin{array}{l}0.00,0.24,0.00 \\
0.24,0.42,0.42\end{array}$} & 0.42 & & \multicolumn{2}{|c|}{0.00} & & \multicolumn{2}{|c|}{0.37} & $0.22,0.07,0.22$ & \multicolumn{2}{|c|}{0.17} \\
\hline \multirow[t]{2}{*}{1} & $\{72,63,30\}$ & $\begin{array}{l}\simeq(\mathbf{0 1} \overline{11}) \\
<\overline{\mathbf{2} 11}>\end{array}$ & $\begin{array}{l}0.26,0.28,0.24 \\
0.19,0.48,0.31\end{array}$ & 0.48 & \multirow{2}{*}{0.11} & $0.07,0.23,0.00$ & 0.15 & \multirow{2}{*}{0.18} & $0.02,0.07,0.00$ & 0.03 & \multirow{2}{*}{0.06} & $0.03,0.13,0.01$ & 0.06 & \multirow{2}{*}{0.07} \\
\hline & $\{60,45,18\}$ & $\begin{array}{l}\sim(01 \overline{1} 1) \\
<1101>\end{array}$ & $\begin{array}{l}0.10,0.21,0.21 \\
0.14,0.34,0.03\end{array}$ & 0.34 & & $0.30,0.34,0.03$ & 0.22 & & $0.00,0.23,0.07$ & 0.10 & & $0.04,0.16,0.06$ & 0.09 & \\
\hline \multirow{2}{*}{2} & $\{90,30,0\}$ & $\begin{array}{l}(\overline{\mathbf{1} 2 \overline{1} 1}) \\
\langle\overline{12} \mathbf{1 1}\rangle\end{array}$ & $\begin{array}{l}0.12,0.19,0.00, \\
0.07,0.17,0.00\end{array}$ & 0.19 & \multirow{2}{*}{0.28} & $0.15,0.43,0.22$ & 0.27 & \multirow{2}{*}{0.31} & $0.10,0.32,0.00$ & 0.14 & \multirow{2}{*}{0.14} & $0.00,0.10,0.16$ & 0.09 & \multirow{2}{*}{0.08} \\
\hline & $\{90,30,60\}$ & $\begin{array}{l}(11 \overline{2} 1) \\
\langle\overline{1121}\rangle\end{array}$ & $\begin{array}{l}0.18,0.19,0.07 \\
0.34,0.04,0.37\end{array}$ & 0.37 & & $0.27,0.33,0.42$ & 0.34 & & $0.01,0.23,0.17$ & 014 & & $0.04,0.04,0.16$ & 0.08 & \\
\hline 4 & $\begin{array}{l}\{69 ., 45,18\} \\
\{39,45,18\}\end{array}$ & $\begin{array}{l}\simeq(\mathbf{0 1} \overline{1} 1) \\
\langle\overline{1101}\rangle\end{array}$ & $\begin{array}{l}0.22,0.11,0.39 \\
0.10,0.23,0.19\end{array}$ & \multicolumn{2}{|c|}{0.39} & $0.24,0.35,0.08$ & \multicolumn{2}{|c|}{0.22} & $0.30,0.04,0.14$ & \multicolumn{2}{|c|}{0.18} & $0.07,0.15,0.00$ & \multicolumn{2}{|c|}{0.07} \\
\hline \multirow{2}{*}{8} & $\{0,60,30\}$ & $\begin{array}{l}\simeq(\mathbf{0 1 \overline { 1 } 1}) \\
\langle 2 \overline{\mathbf{1 1} 0}>\end{array}$ & $\begin{array}{l}0.00,0.41,0.41 \\
0.27,0.00,0.27\end{array}$ & 0.41 & \multirow{2}{*}{0.45} & $0.00,0.00,0.00$ & 0.00 & \multirow{2}{*}{0.06} & $0.04,0.28,0.22$ & 0.21 & \multirow{2}{*}{0.11} & $0.07,0.07,0.26$ & 0.13 & \multirow{2}{*}{0.11} \\
\hline & $\{90,60,18\}$ & $\begin{array}{l}\simeq(\mathbf{0 1 1 1}) \\
\langle 0 \overline{\mathbf{1} 11}\rangle\end{array}$ & $\begin{array}{c}0.23,0.37,0.49, \\
0.18,0.27,0.28\end{array}$ & 0.49 & & $0.03,0.21,0.12$ & 0.12 & & $0.00,0.04,0.00$ & 0.02 & & $0.06,0.12,0.00$ & 0.09 & \\
\hline
\end{tabular}

As twinning is suppressed, the operation of basal slip is considered as the major mechanism during compressive deformation of the processed materials. According to the reported data, the critical resolved shear stresses (CRSS) for basal slip AZ31 alloy is $2 \mathrm{MPa}$ [35]. Thus it can be simply provided during compression tests of the ABEed alloy. However, lower mean grain sizes of the alloy introduce higher strengthening for basal slip-dominated flow. Moreover, since the intensity of basal plane was decreased in multi-pass ABEed alloy, the contribution of easy basal slip is expected to be reduced.

To better study the deformation behavior of the ABEed material, the evolution of work hardening rate $\left(\frac{\partial \sigma}{\partial \varepsilon}=\theta\right)$ against flow stress was presented in Fig. 7, where $\sigma$ and $\varepsilon$ are the macroscopic true stress and true plastic strain, respectively. All of the curves show first a steep hardening decrease, due to a short elastoplastic transition, followed by stage II of work hardening. In the as-received material, stage II is more extended, where the hardening rate increases with the stress. This observation is connected to the occurrence of extensive twinning. Barnett et. al. [36] believed that twinning introduces additional barriers to dislocation movement, something that, at its strongest, is equivalent to reducing the grain size. However, Knezevic et. al. [37] supposed that the trend of hardening is resulted from the fact that twinning in $\mathrm{Mg}$ reorients the lattice to "hard" crystallographic orientations.

In single-pass processed alloy, the ascending hardening rate is still upheld at stage II, though a lower level of hardening rate is reached. Again, the hardening behavior is related to the formation of twins within the large initial grains had been remained unrecrystallized. It has been found that an introduction of twinning as low as $10 \%$ volume fraction will have an appreciable effect on the hardening behavior of magnesium alloys [38]. As the number of passes increased and the mean grain size decreased, the degree of work hardening rate is lowered. Similar results were reported by Del valle [39] and Barnett [36].

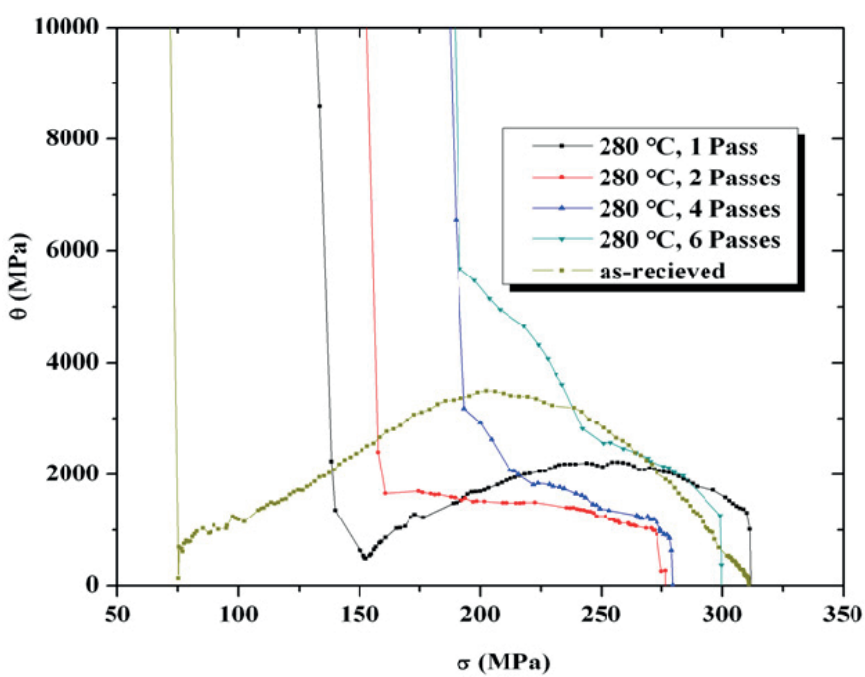

Fig.7 . Macroscopic work hardening rate versuse flow stress during compressive deformation of as-received and ABEed experimental alloy

A change in deformation mechanisms with decreasing grain size may give a plausible explanation for the decrease in hardening rate. Beside suppression of twinning which means a reduction in twin induced hardening, texture hardening should be taken into account. The weakening of basal texture with increasing number of deformation passes, may give rise to the premature activation of non-basal slip during compression. The data in TABLE 1 implied that both prismatic and pyramidal slip favors in the ABEed materials. According to the lower CRSS for prismatic slip, compared with pyramidal slip, a higher relative activity of prismatic is anticipated. However, the CRSS for pyramidal slip is so large and Koike [40] reported that when the compressive flow stress increases to a large value of more than $200 \mathrm{MPa}$ the activation of the $<\mathrm{c}+\mathrm{a}>$ slip is possible. Because of constraint by neighboring grains in polycrystalline magnesium, strain incompatibility at grain boundaries may cause additional stress [41]. This compatibility 

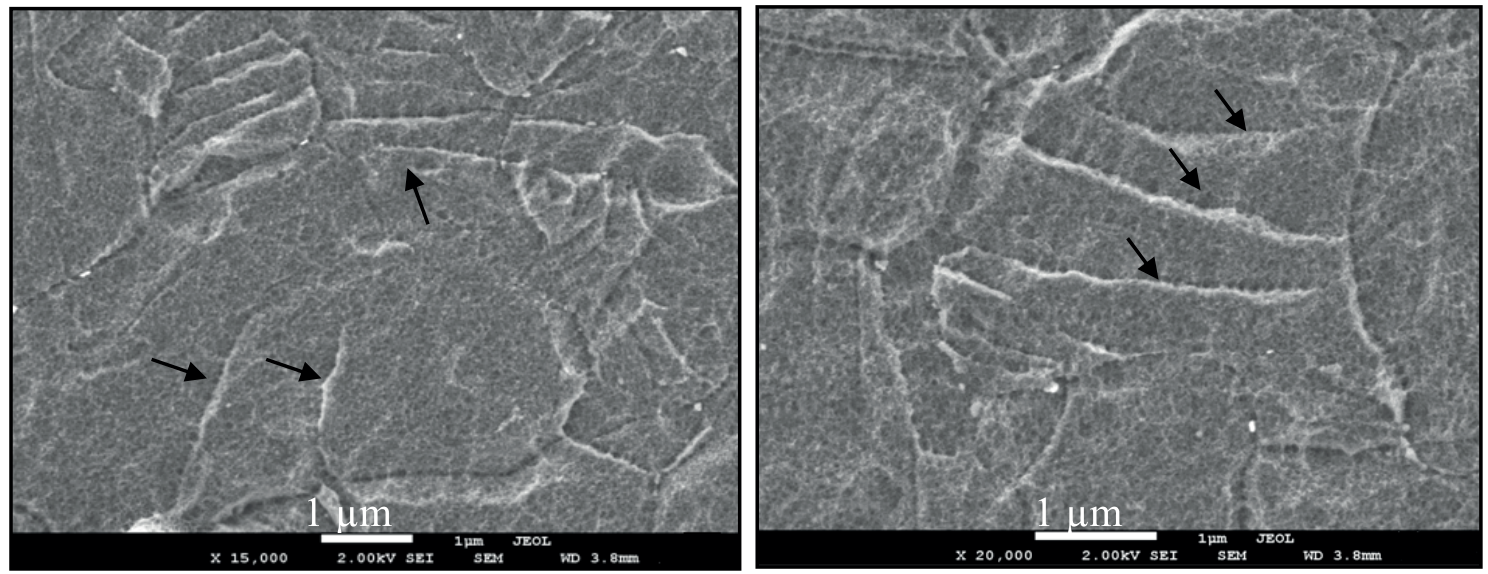

Fig.8 . FESEM images of shearing region near grain boundaries of ABE processed AZ31 alloy developed during compressive deformation

stress gives rise to the activation of nonbasal dislocations in the region within several microns from grain boundaries [40]. So it is rationalize to assume that the compatibility stress influences the entire grain volume in the ultrafine/nano grained magnesium [40]. Thus, the compatibility stress may provide the CRSS for the activation of pyramidal slip and restrict the operation of basal and prismatic slip systems. In this stage of compressive deformation, it is generally known that the flow stress increases very rapidly, leading to final failure. In fact the relative activity of pyramidal slip coincide with the appearance of stage III of hardening, characterized by a linear decrease of the work hardening rate which leads to neck formation. Accordingly, the dominance of compatibility stress in the materials with finer grain size provides the activation stress for $<\mathrm{c}+\mathrm{a}\rangle$ slip and limits the stable hardening at lower strain. This can be understood in light of the report by Yoshinaga et al. [42], in that the $<\mathrm{c}+\mathrm{a}>$ dislocations are split to mobile $<\mathrm{a}>$ and immobile $<\mathrm{c}>$ components which contribute to severe strain hardening, causing harmful effects on formability at room temperature. This explanation rationalized higher maximum stress as well as lower strain-to-fracture obtained for the material with lower mean grain size.

This illustrated that the deformation of grains of nano and submicron sizes was accompanied by strain localization near the grain boundaries. FESEM results, typically showed in Fig. 8 , depicted that the grain boundary regions develop shearing with some degree of superimposed compression. It is speculated that the high dislocation density at the vicinity of grain boundaries exhausted the local hardenability of materials, where the concentrated stress cause the deformation to be followed in narrow shear regions of internally localized flow. The latter features may be considered as the short cut path toward premature cracking.

\section{Conclusion}

The compressive deformation behavior of an ultrafine/ nano grained AZ31 magnesium alloy was evaluated by employing uniaxial compression tests. The results showed that grain refinement as well as texture modifications may increase yield and maximum compressive strain. Grain refining down to the ultrafine and nano scale increased the CRSS required for twinning, while the weakened intensity of basal texture concurrently invoked higher yield stress. Texture analysis implied that both prismatic and pyramidal slip possess proper orientation factor to be activated during compression test of the processed materials. The lower was the mean grain size of the experimental alloy, the higher MCS and the lower strainto-fracture were obtained, due to the compatibility stress contribute during deformation of magnesium alloys.

\section{REFERENCES}

[1] M. Yoo, Metallurgical Transactions A 12, 409-418 (1981).

[2] S. Fatemi-Varzaneh, A. Zarei-Hanzaki, M. Haghshenas, Journal of Alloys and Compounds 475, 126-130 (2009).

[3] A. Beer, in, Deakin University, 2004. PhD Thesis.

[4] Y. Chen, Q. Wang, J. Lin, L. Zhang, C. Zhai, Journal of Materials Science 42, 7601-7603 (2007).

[5] R. Figueiredo, P. Cetlin, T. Langdon, Acta Materialia 55, 47694779 (2007).

[6] R.B. Figueiredo, T.G. Langdon, Journal of Materials Science 44, 4758-4762 (2009).

[7] J. Wang, D. Zhang, Y. Li, Z. Xiao, J. Fouse, X. Yang, Materials \& Design 86, 526-535, (2015).

[8] H. Wang, P. Wu, J. Wang, Computational Materials Science 96, 214-218 (2015).

[9] W. Kim, C. An, Y. Kim, S. Hong, Scripta Materialia 47, 39-44 (2002).

[10] J. Xing, X. Yang, H. Miura, T. Sakai, Materials Transactions 49, 69-75 (2008)

[11] W. Yuan, S. Panigrahi, J.Q. Su, R. Mishra, Scripta Materialia 530, 994-997 (2011).

[12] Z. Zuberova, Y. Estrin, T. Lamark, M. Janecek, R. Hellmig, M. Krieger, Journal of Materials Processing Technology 184, 294-299 (2007).

[13] H. Miura, T. Maruoka, X. Yang, J. Jonas, Scripta Materialia 66, 49-51 (2011).

[14] H. Miura, G. Yu, X. Yang, Materials Science and Engineering: A, 528, 6981-6992 (2011).

[15] M. Pérez-Prado, O. Ruano, Scripta Materialia 51, 1093-1097 (2004).

[16] C. Su, L. Lu, M. Lai, Materials Science and Engineering: A 434, 227-236 (2006). 
[17] C. Xu, Z. Horita, T.G. Langdon, Acta Materialia 55, 203-212 (2007).

[18] Y. Wang, E. Ma, Acta Materialia 52, 1699-1709 (2004).

[19] Q. Yang, A. Ghosh, Acta Materialia 54, 5159-5170 (2006).

[20] Z. Zúberová, Y. Estrin, T. Lamark, M. Janecek, R. Hellmig, M. Krieger, Journal of Materials Processing Technology 184, 294-299 (2007).

[21] S. Fatemi-Varzaneh, A. Zarei-Hanzaki, Materials Science and Engineering: A 504, 104-106, (2009).

[22] S. Fatemi-Varzaneh, A. Zarei-Hanzaki, M. Naderi, A.A. Roostaei, Journal of Alloys and Compounds 507, 207-214 (2010).

[23] S. Fatemi-Varzaneh, A. Zarei-Hanzaki, R. Vaghar, J. Cabrera, Materials Science and Engineering: A 551, 128-132 (2012).

[24] S. Fatemi-Varzaneh, A. Zarei-Hanzaki, Materials Science and Engineering: A 528, 1334-1339 (2011).

[25] S. Fatemi-Varzaneh, A. Zarei-Hanzaki, H. Paul, Materials Characterization 87, 27-35 (2014).

[26] J. Li, W. Xu, X. Wu, H. Ding, K. Xia, Materials Science and Engineering: A, 528, 5993-5998 (2011).

[27] Q. Yang, A. Ghosh, Acta materialia 54, 5147-5158 (2006).

[28] C. Caceres, C. Davidson, J. Griffiths, C. Newton, Materials Science and Engineering A 325, 344-355 (2002).

[29] Z. Trojanova, C. Caceres, Scripta Materialia 56, 793-796 (2007).

[30] M. Dahms, H.J. Bunge, Journal of Applied Crystallography
22, 439-447 (1989).

[31] M. Barnett, Materials Science and Engineering: A 464, 8-16 (2007).

[32] M. Meyers, O. Vöhringer, V. Lubarda, Acta Materialia 49, 4025-4039 (2001).

[33] R. Lapovok, P. Thomson, R. Cottam, Y. Estrin, Journal of Materials Science 40, 1699-1708 (2005).

[34] S. Yin, C. Wang, Y. Diao, S. Wu, S. Li, Journal of Materials Science \& Technology 27, 29-34, (2011).

[35] Y. Wang, J. Huang, Acta Materialia 55, 897-905 (2007).

[36] M. Barnett, Z. Keshavarz, A. Beer, D. Atwell, Acta Materialia 52, 5093-5103 (2004).

[37] M. Knezevic, A. Levinson, R. Harris, R.K. Mishra, R.D. Doherty, S.R. Kalidindi, Acta Materialia 58, 6330-6242 (2010).

[38] H. Yan, R. Chen, E. Han, Materials Science and Engineering: A 527, 3317-3322 (2010).

[39] J. Del Valle, F. Carreno, O. Ruano, Acta Materialia 54, 42474259 (2006).

[40] J. Koike, Metallurgical and Materials Transactions A 36, 16891696 (2005).

[41] J. Koike, T. Kobayashi, T. Mukai, H. Watanabe, M. Suzuki, K. Maruyama, K. Higashi, Acta Materialia 51, 2055-2065 (2003).

[42] H. Yoshinaga, T. Obara, S. Morozumi, Materials Science and Engineering 12, 255-264 (1973). 
